\title{
Review of Clinical and Operative Recommendations for Ophthalmology Practices During the COVID-19 Pandemic
}

\author{
Cory Hoeferlin $^{1}$ (D) Hamid Hosseini ${ }^{2}$
}

Accepted: 4 November 2020 / Published online: 7 January 2021

(C) Springer Nature Switzerland AG 2021

\begin{abstract}
In response to climbing global case and fatality rates of the novel severe acute respiratory syndrome coronavirus 2 (SARS-CoV2) and its associated disease, COVID-19, ophthalmology practices have modified their clinical and operative approach to patient care in an attempt to reduce spread of the virus. The presence of SARS-CoV-2 viral RNA in the preocular tear film raises speculation that the ocular surface can act as an initial site of infection as well as a potential source of person-to-person viral transmission. More recently, conjunctival specimens and immunohistochemical analyses have identified the presence of cellular surface factors necessary for SARS-CoV-2 infection on the ocular surface. Together, these results highlight the importance of safety measures in ophthalmology practices to prevent transmission of SARS-CoV-2. As ophthalmic exams typically require close proximity between a patient's respiratory tract and the provider, clinical and surgical recommendations are aimed at reducing unnecessary patient-provider interactions. Subspecialty professional guidelines can be used to instruct ophthalmologists on the necessity of various procedures and best practice measures. Ophthalmology practice during the COVID-19 pandemic has been dramatically curtailed in an effort to reduce the risk of transmission and converse valuable personal protective equipment (PPE), and the impacts of the ongoing pandemic on ophthalmology practices will be felt for the foreseeable future.
\end{abstract}

Keywords COVID-19 $\cdot$ SARS-CoV-2 $\cdot$ Ophthalmology

\section{Introduction}

The novel severe acute respiratory syndrome coronavirus 2 (SARS-CoV-2) and its associated disease, COVID-19, have rapidly spread from its apparent origin in Wuhan, China, to nearly every country on Earth [1]. At present, there are nearly 50 million confirmed cases and well over one million deaths globally, though these numbers are almost certainly underreported as a consequence of insufficient testing

This article is part of the Topical Collection on Covid-19

Cory Hoeferlin

choeferlin@mednet.ucla.edu

Hamid Hosseini

hosseini@jsei.ucla.edu

1 Retina Division, Stein Eye Institute, David Geffen School of Medicine, University of California Los Angeles, 100 Stein Plaza, Los Angeles, CA 90095-7002, USA

2 Department of Ophthalmology, Stein Eye Institute, David Geffen School of Medicine, University of California Los Angeles, Los Angeles, CA, USA capabilities and an increasing awareness of minimally or asymptomatic infections [2,3].

Following the first wave of the pandemic, much attention has been devoted to the impact of COVID-19 on healthcare systems and the healthcare personnel at risk of contracting and/or spreading the disease via contact with infected patients, exacerbating by documented shortages in personal protective equipment (PPE), hospital beds, and ventilators [4, 5]. Intense research focused on medical treatment, and vaccine development continues worldwide; however, to date, there remains no effective and widely available treatment or prevention for COVID-19 [6-10]. The knowledge and experience accumulated to date will guide recommendations in the ongoing second wave of the pandemic, which will inevitably reduce patient access to healthcare, both as a means of preserving hospital resources and the reluctance of patients to enter health care facilities.

In response to continuously climbing global case and fatality rates, many regions may again consider regulations aimed at postponing or curtailing non-urgent or emergent medical care, including outpatient visits and non-essential surgical procedures. Almost all disciplines, including ophthalmology, have modified their clinical and operative approach to patient 
care in an attempt to reduce demand on health care systems and reduce viral spread [11]. Consequently, ophthalmologists and patients have been forced to choose between the risk of vision loss from a delay in ophthalmic care and contracting the potentially fatal SARS-CoV-2 virus. Professional guidelines for eye care during this crisis are both necessary and helpful for physicians and patients to navigate the crisis; in the USA, many ophthalmologists have deferred elective procedures since March 2020 in accordance with guidance from the American Academy of Ophthalmology (AAO), American College of Surgeons' (ACS), and Centers for Medicare and Medicaid Services (CMS), with endorsement from a majority of ophthalmic subspecialty professional societies [12-14].

This article attempts to review the ocular manifestations of the SARS-CoV-2 and the impact of the COVID-19 pandemic on the practice of ophthalmology. We will also attempt to summarize recommendations regarding outpatient and perioperative care based on current evidence and guidelines. As more data becomes available, it is likely that the strategies outlined herein will change accordingly.

\section{Ocular Involvement in COVID-19}

Anatomically, the nasolacrimal duct connects the nasal cavity of the upper respiratory tract to the mucosa of the ocular surface, acting as a conduit for pathogens between the eye and the respiratory and gastrointestinal tracts. Conjunctival specimens and immunohistochemical analyses have revealed that the ocular surface and the gastrointestinal tract share receptors necessary for respiratory viral infection. The angiotensinconverting enzyme 2 (ACE2) surface receptor, a metallopeptidase, facilitates spike protein binding on numerous respiratory viruses, including SARS-CoV-2, while the transmembrane protease serine 2 (TMPRSSR) enzyme allows for entry following receptor binding [15-17]. Prior research on coronaviruses following the SARS-CoV outbreak in 2003 revealed viral entry is also modulated by other factors on host cell membranes including heparin sulfate proteoglycans (HSPGs); given the similarities in the spike proteins and entry receptors between the two viruses, it has been postulated that HSPGs, which are also present on the ocular mucosa, may act as an attachment receptor for SARS-CoV-2 [18, 19].

Numerous investigators have also reported the presence of viral RNA in ocular discharge and conjunctival swabs; however, the rate of positives by RT-PCR remains low and attempts to culture SARS-CoV-2 from the preocular tear film has thus far been unsuccessful [20-22]. As such, the infectivity and clinical importance of tears as a viral transmission vector is not well understood, yet a growing body of evidence indicates that SARS-CoV-2 can cause ocular abnormalities in infected patients.
Studies suggest that conjunctival abnormalities are present in up to $31.6 \%$ of patients with a COVID-19 diagnosis, with some patients reporting conjunctivitis as the first symptom $[23,24]$. In addition, multiple case reports have identified a potential association between COVID-19 and Kawasaki Disease $(\mathrm{KD})$ in children, a symptom of which can include significant ocular injection [25, 26]. Because of this association, pediatric providers must maintain a high suspicion for the disease in COVID-19-positive patients, especially in those who present with conjunctivitis. These findings raise speculation that the ocular surface may act as an initial site of infection as well as a potential source of person-to-person viral transmission and highlight the importance of safety measures in ophthalmology practices, including facemasks and ocular contact precautions in order to prevent transmission of SARSCoV-2.

\section{Impacts of COVID-19 on the Practice of Ophthalmology}

\section{Intake Precautionary Measures}

In accordance with many governmental and medical governing board regulations, patients are advised to avoid unnecessary travel to healthcare facilities in order to minimize the risk of exposure to SARS-CoV-2 and prioritize PPE allocation to frontline healthcare workers [27]. Like other medical specialties, ophthalmology providers are advised to defer many non-urgent or emergent appointments. Many providers have responded by taking advantage of relaxed regulations on telemedicine by expanding virtual services to maintain relationships with patients and preserve continuity of care rather than canceling appointments outright [28-30].

Of unique concern to ophthalmology clinics is the advanced average age the patient population. As many of the common ocular pathologies tend to affect older patients, including cataracts, glaucoma, and age-related macular degeneration (ARMD), these patients are at higher risk for adverse effects and death from COVID-19 [31,32]. Accordingly, both physicians and patients must weigh the risks and benefits of in-person visits.

In cases where routine visits are deferred, physicians must counsel patients on early signs and symptoms of visionthreatening sequelae. Recent research on ophthalmic emergency services at a tertiary hospital has identified a concerning decrease in consultations for urgent pathologies including uveitis, retinal detachments, and macular pathologies, implying that patients may be either unaware of symptom urgency or otherwise reluctant to access the healthcare services necessary to manage important eye diseases [33].

In cases where in-person visits are indicated, it is recommended that all patients be screened for COVID-19 symptoms 
prior to entering a healthcare facility through a combination of questions aimed at eliciting symptoms and exposures as well as objective screening mechanisms such as body temperature measurements. Patients and staff are advised to follow "social distancing" practices, maintaining at least six feet (or $2 \mathrm{~m}$ ) between others in queues and waiting rooms [34, 35]. Given the presence of visual deficits in the ophthalmology patient population, caretakers often accompany patients to clinics; when applicable, all persons accompanying an ophthalmology patent should receive the same screening for COVID-19 and participate in precautionary measures.

\section{Clinical Precautionary Measures}

As ophthalmic exams typically require close proximity between a patient's respiratory tract and the provider, clinicians are advised to use appropriate PPE when examining a patient, including facemasks and plastic slit lamp shields to minimize the risk of transmission [27]. Physicians should also attempt to minimize procedures that cause ocular irritation in order to prevent patients from rubbing or touching their eyes or faces. If such procedures are necessary, physicians must warn patients about the increased risk of contracting the disease from hand-to-face contact.

Clinical scenarios involving ocular manipulation are of particular concern given the possible presence of the virus in the preocular tear film; such procedures should be limited to those patients with clear indications, as infectious aerosol droplets can remain suspended for $3 \mathrm{~h}$ or more [36]. Standard examination techniques require addition precautionary measures to prevent viral transmission; for example, applanation-based tonometry for the measurement of intraocular pressure (IOP) has the potential for direct cross-contamination from the probe tip while non-contact tonometry has the potential to aerosolize the virus from the ocular surface [36, 37]. Lastly, it is imperative that all surfaces and examination tools, including slit lamps, lenses, and imaging modalities, be properly disinfected between patient contacts, as SARS-CoV-2 can survive for many hours on surfaces $[4,36]$.

Within the field of ophthalmology, many subspecialties face unique SARS-CoV-2 considerations, which we briefly summarize below.

\section{Retina}

The patient population in retina clinics is unique given the high percentage of elderly patients and the presence of comorbidities, placing these patients at a higher risk for severe illness from COVID-19. Additionally, many visits involve an intravitreal injection or require a fundus examination to prevent permanent vision loss, neither of which is amenable to telemedicine platforms [38, 39]. For patients undergoing intravitreal injection therapies (e.g., wet age-related macular degeneration or diabetic retinopathy), retina specialists would benefit from triaging patients to identify those at greatest risk of permanent vision loss and prioritize treatment visits over monitoring visits [38]. To further reduce patient risk, it is vital to enforce established policies such as not talking during injections and utilizing appropriate PPE for both patients and providers. Additionally, in order to minimize the number of clinic visits during the pandemic, clinicians may choose to transition to same-day bilateral injections and implement a treat and extend policy when feasible [39].

\section{Ocular Oncology}

Patients with ocular tumors present unique challenges to ophthalmologists given that ocular tumors are potentially fatal, yet mainstays of cancer treatment involve systemic immunosuppression, increasing the risk of developing COVID-19 [39]. Accordingly, treatment decisions should be made based on the individual risk-benefit profile of each patient; while some stable patient interactions are being shifted to telemedicine platforms, many others have chosen not to delay established treatment protocols, particularly in children, new patients, and those with active disease. Urgent procedures in the field of ocular oncology include orbital biopsy for suspected malignancy, brachytherapy, tumor excision, and enucleation [40, 41].

\section{Uveitis}

Uveitis patients undergoing immunomodulatory therapy (IMT) are classified as high risk in the COVID-19 pandemic [42]. There is ongoing research into the effects of IMTs on coronavirus infection and immune response; however, no formal guidelines have been issued to providers. Uveitis specialists should carefully analyze the risks and benefits associated with in-person encounters when deciding on a treatment course.

\section{Surgical Precautionary Measures}

Early in the pandemic, most elective surgeries were postponed in order to preserve PPE and reduce COVID-19 transmission. While PPE shortages are now of less concern, many hospitals have maintained a reduced operating room load in order to minimize patient volume and potential staff exposure. For ophthalmologists, priority is given to cases where a delay would result in negative impacts on patient outcome; however, an increasing number of elective surgeries (e.g., cataract extractions with intraocular lens placement) are being performed both to address the accumulated backlog and improve patient quality of life. For such cases, a patient's COVID-19 status should be determined prior to surgery and the appropriate PPE utilized by the surgical team. 
In patients with positive pre-operate PCR testing, it is prudent to consider delaying surgery given the possibility of rapid clinical deterioration and adverse surgical outcomes [43, 44]. Most institutions have developed individual protocols adapted from guidelines of World Health Organization (WHO); however, for patients with no suspicion or evidence of SARVSCoV-2, standard surgical PPE should suffice. For patients who are RT-PCR positive, or with evidence of antibodies to the virus, surgical teams should consider utilizing masks that efficiently filter airborne particle (e.g., N95 respirators), as well as reducing the surgical staff and minimizing in-out traffic in operating rooms [45].

The identification of aerosol-generating procedures is also essential to potential viral transmission to health care personnel [46]. As endotracheal intubation is known to generate aerosols, ophthalmic surgeries performed under general anesthesia may pose additional risk, and appropriate precautions should be used $[47,48]$. Other routine ophthalmic procedures, including those that utilize ultrasound probes in the eye, are unlikely to create aerosol due to the closed nature of the surgical systems, and standard surgical protocols and field sterilization techniques are likely sufficient [44].

\section{Returning to Practice}

Following the first wave of the COVID-19 pandemic, many regions began the process of lifting COVID-19-related restrictions, including the reopening of ambulatory surgery centers (ASCs) and the resumption of limited elective surgeries [49]. While the regulatory environment around the ongoing second wave of the pandemic remains highly variable across regions, practices continue the transition toward normal functioning. This transition should be undertaken in a tiered approach in close coordination with hospital, local, and regional regulatory bodies to ensure patient and provider safety and preserve capacity in the healthcare system $[49,51]$. In addition, the dynamic nature of the pandemic will necessitate ongoing assessment of new trends, data, testing, and treatments, and recommendations need to be reviewed and updated regularly.

For many patients, there is an increased desire to seek overdue clinical care as regulations ease. However, ophthalmology practices must remain vigilant about the possibility of outbreaks and adjust practice accordingly. Until reliable pointof-care testing or effective treatments or vaccines are widely available, ophthalmology practices and clinics should continue to mandate social distancing in waiting rooms, efficient patient turn-over systems to minimize idle time, frequent disinfectant of all patient areas and equipment, and PPE precautions [50]. As these practices will necessitate additional time between patient encounters, ophthalmologists may be forced to decide whether to book fewer patients on a given day or extend clinic hours [51]. Continued expansion of telemedicine platforms will also provide clinicians a way to reduce the burden of high patient volumes as clinics begin to reopen.

Finally, ophthalmology practices or healthcare systems may wish to institute a supervisory committee to oversee infection control measures and audit healthcare practices based on patterns of transmission (e.g., patient to patient, healthcare personnel to patient, patient to healthcare personnel, and surface to patient). Regional and global physician working groups may be utilized to share professional experiences and perspectives on the effect of the pandemic on practice, allowing the rapid dissemination of trends and best practices [32]. Adherence to best practice measures and active surveillance of COVID-19 remains crucial for minimizing viral transmission risk.

\section{Conclusion}

Ophthalmology practice during the COVID-19 pandemic has been dramatically curtailed in an effort to reduce the risk of transmission and converse valuable PPE. As some regions report progress combating the pandemic, the scope of practice will broaden accordingly; however, caution is advised given the dynamic nature of the situation and the ongoing second wave of the pandemic. The impacts of the pandemic on ophthalmology practices will be felt for the foreseeable future, even after effective point-of-care testing, treatments, and vaccines are available. The recommendations summarized in this article are a snapshot of current practices, which are rapidly evolving and subject to change. Additionally, all recommendations should be considered in the context of local regulations, institutional policies, and local prevalence of disease.

Authors' Contributions All the authors contributed to the study conception and design. Material preparation, literature review data collection, and analysis were performed by Cory Hoeferlin and Hamid Hosseini. The first draft of the manuscript was written by Cory Hoeferlin, and all the authors commented on previous versions of the manuscript. All the authors read and approved the final manuscript.

Funding This work is supported by an Unrestricted Grant from Research to Prevent Blindness, Inc. to the Department of Ophthalmology at UCLA.

Data Availability Not applicable.

\section{Compliance with Ethical Standards}

Conflict of Interest The authors declare that they have no conflict of interest.

Ethics Approval Not applicable.

Consent to Participate Not applicable. 
Consent for Publication All the authors have granted consent to publish this manuscript as submitted or with any changes deemed necessary by the editorial board.

Code Availability Not applicable.

\section{References}

1. Guan WJ, Ni ZY, Hu Y, Liang WH, Ou CQ, He JX, et al. Clinical characteristics of coronavirus disease 2019 in China. N Engl J Med. 2020;382(18):1708-20. https://doi.org/10.1056/NEJMoa2002032.

2. Johns Hopkins University. COVID-19 Dashboard by the Center for Systems Science and Engineering (CSSE) at Johns Hopkins University. 2020. https://coronavirus.jhu.edu/. Accessed 16 Oct 2020.

3. Bai Y, Yao L, Wei T, Tian F, Jin DY, Chen L, et al. Presumed asymptomatic carrier transmission of COVID-19 [published online ahead of print, $2020 \mathrm{Feb} 21$ ]. JAMA. 2020;323(14):1406-7. https:// doi.org/10.1001/jama.2020.2565.

4. Ong SW, Tan YK, Chia PY, et al. Air, surface environmental, and personal protective equipment contamination by severe acute respiratory syndrome coronavirus 2 (SARS-CoV-2) from a symptomatic patient [published online ahead of print, 2020 Mar 4]. JAMA. 2020;323(16):1610-2. https://doi.org/10.1001/jama.2020.3227.

5. Rowan NJ, Laffey JG. Challenges and solutions for addressing critical shortage of supply chain for personal and protective equipment (PPE) arising from coronavirus disease (COVID19) pandemic - case study from the Republic of Ireland. Sci Total Environ. 2020;725:138532. https://doi.org/10.1016/j.scitotenv.2020. 138532.

6. Fauci AS, Lane HC, Redfield RR. Covid-19 - navigating the uncharted. N Engl J Med. 2020;382:1268-9. https://doi.org/10.1056/ NEJMe2002387.

7. World Health Organization (WHO). Draft landscape of COVID19 candidate vaccines. 2020. https://www.who.int/blueprint/prioritydiseases/key-action/novel-coronavirus-landscape-ncov.pdf. Accessed 16 May 2020.

8. Zhang W, Zhao Y, Zhang F, et al. The use of anti-inflammatory drugs in the treatment of people with severe coronavirus disease 2019 (COVID-19): the experience of clinical immunologists from China. Clin Immunol. 2020;214:108393. https://doi.org/10.1016/j. clim.2020.108393.

9. Gautret P, Lagier J-C, Parola P, Hoang VT, Meddeb L, Mailhe M, et al. Hydroxychloroquine and azithromycin as a treatment of COVID-19: results of an open-label non-randomized clinical trial. Int J Antimicrob Agents. 2020;56:105949. https://doi.org/10.1016/ j.ijantimicag.2020.105949.

10. Ahn DG, Shin HJ, Kim MH, Lee S, Kim HS, Myoung J, et al. Current status of epidemiology, diagnosis, therapeutics, and vaccines for novel coronavirus disease 2019 (COVID-19). J Microbiol Biotechnol. 2020;30(3):313-24. https://doi.org/10.4014/jmb.2003.03011.

11. Harris, PA. AMA praises government on elective surgery guidelines during pandemic. 2020. https://www.ama-assn.org/presscenter/ama-statements/ama-praises-government-elective-surgeryguidelines-during-pandemic. Accessed 4 May 2020.

12. American Academy of Ophthalmology. Recommendations for urgent and nonurgent patient care. 2020. https://www.aao.org/ headline/new-recommendations-urgent-nonurgent-patient-care. Accessed 10 May 2020

13. Centers for Medicare \& Medicaid Services. Non-emergent, elective medical services, and treatment recommendations. 2020. https:// www.cms.gov/files/document/cms-non-emergent-electivemedical-recommendations.pdf. Accessed 6 May 2020.
14. American College of Surgeons. COVID-19: elective case triage guidelines for surgical care. 2020. https://www.facs.org/covid-19/ clinical-guidance/elective-case. Accessed 6 May 2020.

15. Hoffmann M, Kleine-Weber H, Schroeder S, et al. SARS-CoV-2 cell entry depends on ACE2 and TMPRSS2 and is blocked by a clinically proven protease inhibitor. Cell. 2020;181(2):271-280.e8. https://doi.org/10.1016/j.cell.2020.02.052.

16. Shang J, Ye G, Shi K, Wan Y, Luo C, Aihara H, et al. Structural basis of receptor recognition by SARS-CoV-2. Nature. 2020;581(7807):221-4. https://doi.org/10.1038/s41586-020-2179y.

17. Lu R, Zhao X, Li J, Niu P, Yang B, Wu H, et al. Genomic characterisation and epidemiology of 2019 novel coronavirus: implications for virus origins and receptor binding. Lancet. 2020;395(10224):565-74. https://doi.org/10.1016/S01406736(20)30251-8.

18. Coulson-Thomas VJ, Chang SH, Yeh LK, Coulson-Thomas YM, Yamaguchi Y, Esko J, et al. Loss of corneal epithelial heparan sulfate leads to corneal degeneration and impaired wound healing. Invest Ophthalmol Vis Sci. 2015;56(5):3004-14. https://doi.org/10. 1167/iovs.14-15341.

19. Coroneo TM. The eye as the discrete but defensible portal of coronavirus infection [published online ahead of print, 2020 May 21]. Ocul Surf. 2020;S1542-0124(20):30089-6. https://doi.org/10. 1016/j.jtos.2020.05.011.

20. Xia J, Tong J, Liu M, Shen Y, Guo D. Evaluation of coronavirus in tears and conjunctival secretions of patients with SARS-CoV-2 infection [published online ahead of print, $2020 \mathrm{Feb} 26$ ]. J Med Virol. 2020;92:589-94. https://doi.org/10.1002/jmv.25725.

21. Chan WM, Yuen KS, Fan DS, Lam DS, Chan PK, Sung JJ. Tears and conjunctival scrapings for coronavirus in patients with SARS. Br J Ophthalmol. 2004;88(7):968-9. https://doi.org/10.1136/bjo. 2003.039461.

22. Zhang X, Chen X, Chen L, Deng C, Zou X, Liu W, et al. The evidence of SARS-CoV-2 infection on ocular surface [published online ahead of print, 2020 Apr 11]. Ocul Surf. 2020;18(3):3602. https://doi.org/10.1016/j.jtos.2020.03.010.

23. Li JO, Lam DSC, Chen Y, Ting DSW. Novel coronavirus disease 2019 (COVID-19): the importance of recognising possible early ocular manifestation and using protective eyewear. $\mathrm{Br} \mathrm{J}$ Ophthalmol. 2020;104(3):297-8. https://doi.org/10.1136/ bjophthalmol-2020-315994.

24. Wu P, Duan F, Luo C, Liu Q, Qu X, Liang L, et al. Characteristics of ocular findings of patients with coronavirus disease 2019 (COVID-19) in Hubei Province, China [published online ahead of print, 2020 Mar 31]. JAMA Ophthalmol. 2020;138(5):575-8.

25. Harahsheh AS, Dahdah N, Newburger JW, et al. Missed or delayed diagnosis of Kawasaki disease during the 2019 novel coronavirus disease (COVID-19) pandemic [published online ahead of print, 2020 May 3]. J Pediatr. 2020;S0022-3476(20):30556-4. https:// doi.org/10.1016/j.jpeds.2020.04.052.

26. Jones VG, Mills M, Suarez D, et al. COVID-19 and Kawasaki disease: novel virus and novel case [published online ahead of print, 2020 Apr 7]. Hosp Pediatr. 2020;hpeds.2020-0123:537-40. https:// doi.org/10.1542/hpeds.2020-0123.

27. Olivia Li JP, Shantha J, Wong TY, Wong EY, Mehta J, Lin H, et al. Preparedness among ophthalmologists: during and beyond the COVID-19 pandemic. Ophthalmology. 2020;127(5):569-72. https://doi.org/10.1016/j.ophtha.2020.03.037.

28. Saleem SM, Pasquale LR, Sidoti PA, Tsai JC. Virtual ophthalmology: telemedicine in a Covid-19 era [published online ahead of print, 2020 Apr 30]. Am J Ophthalmol. 2020;S0002-9394(20): 30214-2. https://doi.org/10.1016/j.ajo.2020.04.029.

29. Centers for Medicare and Medicaid Services. Medicare telemedicine health care provider fact sheet. 2020. https://www.cms.gov/ 
newsroom/fact-sheets/medicare-telemedicine-health-care-providerfact-sheet. Accessed 29 April 2020.

30. De Lott LB, Newman-Casey PA, Lee PP, et al. Change in ophthalmic clinicians' attitudes toward telemedicine during the coronavirus 2019 pandemic. [published online ahead of print, $2020 \mathrm{Jul} 17$ ]. Telemed J E Health. 2020. https://doi.org/10.1089/tmj.2020.0222.

31. Liebmann JM. Ophthalmology and glaucoma practice in the COVID-19 era [published online ahead of print, 2020 Apr 14]. J Glaucoma. 2020;29:407-8. https://doi.org/10.1097/IJG. 0000000000001519.

32. Toro MD, Brézin AP, Burdon M, Cummings AB, Evren Kemer O, Malyugin BE, et al. Early impact of COVID-19 outbreak on eye care: insights from EUROCOVCAT group. Eur J Ophthalmol. 2020:112067212096033. https://doi.org/10.1177/ 1120672120960339 .

33. García Lorente M, Zamorano Martín F, Rodríguez Calvo de Mora M, Rocha-de-Lossada C. Impact of the COVID-19 pandemic on ophthalmic emergency services in a tertiary hospital in Spain. Eur J Ophthalmol. 2020:112067212095832. https://doi.org/10.1177/ 1120672120958324.

34. Romano MR, Montericcio A, Montalbano C, Raimondi R, Allegrini D, Ricciardelli G, et al. Facing COVID-19 in ophthalmology department. Curr Eye Res. 2020;45(6):653-8. https://doi.org/ 10.1080/02713683.2020.1752737.

35. Lim LW, Yip LW, Tay HW, Ang XL, Lee LK, Chin CF, et al. Sustainable practice of ophthalmology during COVID-19: challenges and solutions [published online ahead of print, 2020 Apr 21]. Graefes Arch Clin Exp Ophthalmol. 2020;258:1-10. https://doi.org/10.1007/s00417-020-04682-z.

36. van Doremalen N, Bushmaker T, Morris DH, Holbrook MG, Gamble A, Williamson BN, et al. Aerosol and surface stability of SARS-CoV-2 as compared with SARS-CoV-1. N Engl J Med. 2020;382:1564-7. https://doi.org/10.1056/nejmc2004973.

37. Britt JM, Clifton BC, Barnebey HS, Mills RP. Microaerosol formation in noncontact 'air-puff' tonometry. Arch Ophthalmol. 1991;109(2):225-8. https://doi.org/10.1001/archopht.1991. 01080020071046.

38. Shmueli O, Chowers I, Levy J. Current safety preferences for intravitreal injection during COVID-19 pandemic [published online ahead of print, 2020 May 4]. Eye (Lond). 2020;34:1-3. https://doi. org/10.1038/s41433-020-0925-x.

39. Korobelnik JF, Loewenstein A, Eldem B, Joussen AM, Koh A, Lambrou GN, et al. Guidance for anti-VEGF intravitreal injections during the COVID-19 pandemic. Graefes Arch Clin Exp Ophthalmol. 2020;258(6):1149-56. https://doi.org/10.1007/ s00417-020-04703-x.

40. Skalet AH, Allen RC, Shields CL, Wilson MW, Mruthyunjaya P, Gombos DS. Considerations for the management and triage of ocular oncology cases during the COVID-19 pandemic. Ocul Oncol Pathol. 2020;6(3):1-4. Published 2020 Apr 21. https://doi.org/10. $1159 / 000507734$.
41. Stuart A. COVID-19 pandemic: ocular tumor triage and care. EyeNet. 2020;23(5). https://www.aao.org/eyenet/article/covid-19pandemic-ocular-tumor-triage-and-care?april-2020. Accessed April 2020.

42. Smith JR, Lai TY. Managing uveitis during the COVID-19 pandemic [published online ahead of print, 2020 May 19]. Ophthalmology. 2020;S0161-6420(20):30480-2. https://doi.org/ 10.1016/j.ophtha.2020.05.037.

43. Forrester JD, Nassar AK, Maggio PM, Hawn MT. Precautions for operating room team members during the COVID-19 pandemic. J Am Coll Surg. 2020;230(6):1098-101. https://doi.org/10.1016/j. jamcollsurg.2020.03.030.

44. COVIDSurg Collaborative. Global guidance for surgical care during the COVID-19 pandemic [published online ahead of print, 2020 Apr 15]. Br J Surg. 2020;107:1097-103. https://doi.org/10.1002/ bjs.11646.

45. Brindle ME, Gawande A. Managing COVID-19 in surgical systems [published online ahead of print, 2020 May 21]. Ann Surg. 2020;272:e1-2. https://doi.org/10.1097/SLA.0000000000003923.

46. Tang JW, Li Y, Eames I, Chan PKS, Ridgway GL. Factors involved in the aerosol transmission of infection and control of ventilation in healthcare premises. J Hosp Infect. 2006;64:100-14. https://doi.org/10.1016/j.jhin.2006.05.022.

47. Wax RS, Christian MD. Practical recommendations for critical care and anesthesiology teams caring for novel coronavirus (2019nCoV) patients. Can J Anesth. 2020;67:568-76. https://doi.org/ 10.1007/s12630-020-01591-x.

48. Kaye K, Paprottka F, Escudero R, Casabona G, Montes J, Fakin R, et al. Elective, non-urgent procedures and aesthetic surgery in the wake of SARS-COVID-19: considerations regarding safety, feasibility and impact on clinical management [published online ahead of print, 2020 May 14]. Aesthet Plast Surg. 2020;44:1-29. https:// doi.org/10.1007/s00266-020-01752-9.

49. Shahraz S, Mohammadi SF, Safi S. The role of guidance and planning on safety of ophthalmic practice during the COVID-19 pandemic. J Ophthalmic Vis Res. 2020;15(3):275-8. https://doi.org/10. 18502/jovr.v15i3.7445.

50. Parke DW. Ophthalmology after coronavirus disease 2019 (COVID-19): transition back to patient care. JAMA Ophthalmol. 2020:599-600. Published online May 04, 2020. https://doi.org/10. 1001/jamaophthalmol.2020.2004.

51. Dexter F, Elhakim M, Loftus RW, Seering MS, Epstein RH. Strategies for daily operating room management of ambulatory surgery centers following resolution of the acute phase of the COVID-19 pandemic [published online ahead of print, 2020 Apr 29]. J Clin Anesth. 2020;64:109854. https://doi.org/10.1016/ j.jclinane.2020.109854.

Publisher's Note Springer Nature remains neutral with regard to jurisdictional claims in published maps and institutional affiliations. 